\title{
Individual differences and course attendance: Why do students skip class?
}

Luke K. Fryer: lukefryer@yahoo.com, University of Sydney, Sydney School of Education and Social Work; University of Hong Kong, CETL (contact author)

Paul Ginns: paul.ginns@sydney.edu.au, University of Sydney, Sydney School of Education and Social Work

Mark Howarth: howarth@ip.kyusan-u.ac.jp, Kyushu Sangyo University, Language

Education and Research Centre

Charles Anderson: charlesanderson@ip.kyusan-u.ac.jp, Kyushu Sangyo University, Language Education and Research Centre

Shuichi Ozono: ozono@ip.kyusan-u.ac.jp; Kyushu Sangyo University, Language Education and Research Centre

The first author's contribution was made possible by a Thomas and Ethel Mary Ewing Scholarship.

This is the accepted manuscript.

ONLINE LOCATION:

http://www.tandfonline.com/doi/full/10.1080/01443410.2017.1403567

\section{Please cite this article as:}

Fryer, L. K., Ginns, P., Howarth, M., Anderson, C., \& Ozono, S. (2017). Individual differences and course attendance: Why do students skip class? Educational Psychology, 1-17. doi:10.1080/01443410.2017.1403567

\section{Individual differences and course attendance: Why do students skip class?}




\begin{abstract}
Individual differences are theorised as being key predictors of students’ lecture attendance. Understanding students' (lack of) motivation for studying is an essential first step in supporting these individual differences and potentially increasing class/lecture attendance. The current study explored the role of students' deficits in motivations (ability/effort/ task value) for studying in predicting class attendance, controlling for prior competence and academic self-concept in the domain of study. Second-year students ( $n=219 ;$ Female=40) undertaking three semester-long courses in English as a foreign language participated in the year-long study. The structural model tested included prior achievement and self-concept (Time-1; 15 weeks prior), the motivational deficits for studying in the course (Time-2; ability, effort and task value), and class attendance across the two semesters of study. Self-concept negatively predicted all motivational deficits (moderate-large effects), and positively predicted attendance. Two of the motivational deficits (ability and effort) also had strongly contrasting effects (positive and negative respectively) on attendance. The implications and practical suggestions for intervention are discussed.
\end{abstract}




\section{Introduction}

Many university instructors begin the year by telling their students how important attendance is. In addition to being true across most courses, in the context of courses designed to support skills development like a foreign language class, the implications of not attending a single class can mean missing an experience which is essential and a part of a sequential development. Meta-analytic findings have demonstrated that class attendance is one of the strongest correlates of course grades (Credé, Roch, \& Kieszczynka, 2010). Beyond attendance for an individual course, patterns in attendance are also important for understanding and intervening in institutional retention at the degree program level (Lotkowski, Robbins, \& Noeth, 2004).

Attendance is a behaviour that is clearly subject to volition/motivation above and beyond the practical restrictions on making it to class (e.g., sickness, competing priorities and lifestyle-related reasons). If university instructors are to support students in coming to class, then understanding the sources of variation in absences is essential. The current study therefore seeks to develop and test a longitudinal, predictive model for understanding why students are absent from lectures based primarily on their attributions for why they choose not to study.

\section{Attendance}

There has been an ongoing discussion within higher education for at least three decades about the role and importance of lecture attendance. Much of this debate is centred on establishing the role of attendance as a predictor of students' course achievement. Some early studies demonstrated the predictive validity of attendance (e.g., Romer, 1993) and called for future studies to investigate the effect of mandatory policies 
both on attendance and achievement. Citing a handful of studies discussing and empirically examining the effect of mandatory policies, Clair (1999) mounted an argument against such blanket rules. Clair argued, consistent with Hyde and Flournoy's (1986) study in the context of medical education, that attendance policies did not conclusively affect course grades. Hyde and Flournoy pointed out that in their study that many top performers rarely came to class. They even went so far as to suggest that a mandatory policy could have a negative effect on achievement for some students. Clair (1999) concluded by suggesting that achievement is about more than simply getting students to attend, and called for the development of a firm evidence base before making decisions about mandatory policies. She argued that control over students' success should be in their hands, not faculty or administrators'. Clair also suggested that it is motivation that predicts student attendance and that is where future studies should focus.

Studies since Clair’s (1999) call have generally supported the link between attendance and achievement (e.g., Chen \& Lin, 2008; Newman-Ford, Fitzgibbon, Lloyd, \& Thomas, 2008). Studies examining the effect of mandatory policies, however, have often failed to increase achievement despite increasing attendance (e.g., Marburger, 2006) seeming to substantiate Clair's argument. Employing a meta-analytic framework to review available research, Credé et al. (2010) demonstrated that in addition to being an important correlate of achievement (i.e., class grades: $k=69, N=21,195, r=.44$; GPA: $k$ $=33, N=9,243, r=.41$ ), a substantial amount of the shared variance between attendance and achievement was not in common with the other variables examined. Credé et al. also suggested—based on three studies—-that mandatory attendance policies had a small positive effect $(k=3, N=1,421, d=.21)$ on course achievement. Credé et al. called for 
more research into this area and specifically into the individual differences that influence students' attendance.

More recent investigations of the role of attendance in specific educational contexts, such as studying for professional careers like medicine (Bati, Mandiracioglu, Orgun, \& Govsa, 2013) or language-learning courses (Fay, Aguirre, \& Gash, 2013), have pointed out the particularly important role of attendance for knowledge acquisition in these specialist areas. Both the broad role of attendance within course achievement and its particular importance in specific domains of study entreats further research into the individual differences which influence students’ decisions not to attend lectures.

Individual differences predicting attendance. Individual differences are a complex web of inter-related psychological constructs which directly impact an individual's behaviours and resulting performance. In the current study we are concerned specifically with students’ beliefs about why they do not study. We suggest that decisions about whether or not to study and attend class are strongly connected, with the prior being an important predictor of the latter.

Deficits in motivations/beliefs and their role in decision-making or helplessness (i.e., how lack of motivation is related to future behaviour) have substantial theoretical and empirical history (e.g., Abramson, Seligman, \& Teasdale, 1978). Within SelfDetermination Theory (SDT), a lack of motivations (amotivation) is defined as resulting “from not valuing an activity (Ryan, 1995), not feeling competent to do it (Deci, 1975), or not believing it will yield a desired outcome (Seligman, 1975).” (Ryan \& Deci, 2000). French Canadian researchers, working within SDT, constructed a measure of amotivation in formal educational contexts (e.g., Ratelle, Guay, Vallerand, Larose, \& Senécal, 2007; 
Vallerand, Fortier, \& Guay, 1997; Vallerand et al., 1992, 1993). This and corollary research have applied amotivation to domains such as the environment (Pelletier, Dion, Tucson, \& Green-Demers, 1999), high school dropouts (Vallerand \& Bissonnette, 1992), indecision regarding entry into higher education and their resulting persistence (Jung, 2013).

Pelletier and colleagues (Green-Demers, Legault, Pelletier, \& Pelletier, 2008; Legault, Green-Demers, \& Pelletier, 2006; Pelletier, Dion, Tuson, \& Green-Demers, 1999) developed and tested a multi-dimensional model (Academic Motivation Inventory, Legault, et al., 2006) of amotivation within the Self-Determination Theory framework (Deci \& Ryan, 1985). This model described reasons why students failed to study and how this deficit in motivation related to social support, and academic outcomes such as achievement and intention to dropout. This work drew on established theories of selfbeliefs and motivation: task-value (Eccles et al., 1983), effort (Skinner, Wellborn, \& Connell, 1990) and perceived competency (Bandura, 1977; Patrick, Skinner, \& Connell, 1993).

While students' lack of motivation for their studies is certainly an important component of a model seeking to explain absences from class, it is also essential that other known predictors be accounted for. Prior achievement/competence is acknowledged to be a key determinant of class attendance (Credé et al., 2010). Attendance has also been suggested as a mediator for the effect of prior achievement on future achievement. There is substantial evidence to suggest that perceived competence (i.e., self-concept in the current study; Marsh \& Shavelson, 1985) has an additional, separate effect on a range of behaviours related to learning. For example Marsh and Yeung (1997) established that 
academic self-concept is connected to future course selection. From here it is not a long step to hypothesising about academic self-concept's potential role within course attendance. Furthermore, a recent study in the area of another important individual difference (task interest) has suggested that self-concept is important to control for when modelling related individual differences (Fryer, Ainley \& Thompson, 2016). Therefore, as predictor and control, both actual and perceived competence (academic self-concept) are important when seeking to understand the effect of students’ key motivational deficits for studying on their attendance choices.

\section{The current study}

Studying and learning English within Japanese higher education. In the majority of Japanese universities English language studies are compulsory for one or two years. The compulsory nature of these courses suggests that students with a wide variety of interest levels are forced to participate. Research in this area has pointed to a longstanding motivational crisis for English language learning in Japan (Ryan, 2009) and focused on the students’ perceptions of its weak instrumental value (Fryer et al., 2013). Japan's international rankings on English proficiency tests have long suggested that the average Japanese adult student's motivation and engagement are relatively low (i.e., 40 out of 48 internationally; TOEIC Worldwide report, 2015). As course attendance is a crucial observed component of student engagement, it is an essential “first stop” along the road to assessing and beginning to properly address this issue. The institution where the current study took place was aware of the importance of this issue and had long instituted minimum attendance for courses. Recently the institution had taken the first 
step in beginning to measure attendance for all courses through IC (Integrated Circuit) cards.

The current research context. This study was undertaken in the context of first- and second-year compulsory English as a foreign language in a private university in Western Japan. Due to the courses’ compulsory nature, the students varied naturally in their motivations for studying in the course. The three semester-long English language courses which were the context for the current study were a part of a coordinated program: up to two English language speaking/listening and two English language reading/writing courses during students' first two years at university. These courses were a part of the university's fundamental education program common to all departments and aimed at supporting English reading/writing/listening/speaking skills. All students took a test (standardised listening/reading test; for a review see Stewart, Gibson \& Fryer, 2012) prior to the start of classes and were then enrolled in a class appropriate to their level. In this compulsory English language program, classes of the same level used the same study materials (textbooks, weekly online learning and tests; Fryer, et al., 2010; Bovee \& Fryer ; Stewart, Fryer, \& Gibson, 2013; Stewart, Gibson, Fryer, 2012)). End of term standardised competency tests were also shared across all classes. Each semester course was 15 classes in total, once a week, and all first and second-year students at the university generally took three or four of these courses each year. Students usually completed their necessary credits in two years (during a four year degree). 
Eight classes of students were included in the current study: one teacher teaching four classes and two teachers each teaching two classes. Class size ranged between 25 and 30. Classes were strategically chosen to represent the broad range of English language competencies at the university. There were 56 classes in the second-year program, which were organised based on students' prior achievement results. These classes were organised within the university programme into four bands of students (low, intermediate, high and very high) for instructional materials (level of textbooks and online textbook support). All other learning components, including vocabulary materials, weekly, semesterly and annual test were consistent across the program (and the classes sampled). Two classes from each band were selected for the current study in order to obtain a comprehensive sample of students. The choice of participating class was strategic, from amongst nine teachers who were participating in another large longitudinal program of research. Teachers and classes were strategically selected to ensure a range of competency levels and that teachers' were consistent in their instructional and attendance policies.

All teachers participating in the current study employed a policy of up to five absences permitted (2/3 attendance mandatory), with special excuses being given to students who had special reasons for being absent (medical notice, funeral, etc.). All teachers were flexible about the attendance policy and stated the policy at the beginning of the year primarily to encourage students to come. Due to the general attendance policy (2/3 of classes) and the broadly understood importance of participation for language learning, it is reasonable to expect less variance in language class attendance than some other university course contexts. 


\section{Aims and Predictions}

The current study aimed to test a model that would establish the predictive validity of deficits in motivation to study for class attendance. Seeking to control for other relevant predictors, gender (referring to biological sex in the current study), prior competency (score on a prior standardised test; Stewart et al., 2012) and perceived competence (academic self-concept for English as a foreign language) were also included in the model. Figure 1 presents the hypothesised model to be tested. Figure 2 presents the sequence of measurements modelled.

Figure 1 and 2 About Here

Furthermore, we predicted that both prior competence and perceived competence would predict students' motivations to study and their final attendance in the course. Students' motivational deficits were expected to then predict attendance after accounting for prior actual and perceived competence. We also expected the links between of prior competence and perceived competence with attendance to be partially mediated by students' motivational deficits. Due to the lack of prior research in the area of individual differences and attendance, we tested a fully-forward model: all Time-1 variables were modelled as predicting all Time-2 variables and all Time-1/-2 variables were modelled as predicting attendance for three classes within the same coordinated compulsory English program, during the same academic year (modelled as a single latent variable). 


\section{Methods}

\section{Sample}

Second-year students studying in five faculties (Commerce, Economics, Engineering, Information Sciences and Management; $n=219$, Female $=40$ ) studying at one private mid-sized university in Western Japan participated in this study. The university is of mid-tier national ranking and has a strong focus on business and the technical sciences (engineering and computer sciences). As is standard in Japan, nearly all students lived off campus. Consistent with national standards regarding university curricula, students had to complete a set of courses in foreign languages in order to graduate.

Participating students were enrolled in three second-year compulsory English courses, which were embedded in a coordinated program of study. The students' proficiency (based on prior competency test; see Stewart, et al. 2012) ranged from lower intermediate (essential communication) to intermediate communication (strong day-today communication) skills in the English language. Each course was one semester long and consisted of 15 classes in total (five week summer holiday between semesters). Students were informed of the nature of the study and its broad aim of understanding and thereby supporting class attendance. Participation was voluntary and students were offered the option to opt out by simply handing in the class survey incomplete. No students chose to opt out of the study.

\section{Procedures}

Students completed one survey with their achievement test at the end of the prior academic year and a second survey three weeks into the academic year of the study 
(described in the introduction). The in-class survey (12 items in length) took less than 5 minutes to hand out, complete, and pass in. The Time-1 survey (English language academic self-concept) contained four items (e.g., I have always been good at English; I receive good grades in my English classes). This survey was adapted from a widely used academic self-concept survey in Japan (Ichihara \& Arai, 2004), which has been employed successfully in the current research context and elsewhere in Japan (Fryer, 2015; Murayama \& Elliot, 2009).

The in-class survey measuring students' reasons for not studying included three of four scales from the Academic Amotivation Inventory (Legault, 2006). Three (of four) scales from the Academic Amotivation Inventory were adapted (Fryer, 2013) and successfully employed in previous studies examining learning strategies (Fryer, Ginns \& Walker, 2016; Fryer, Ginns \& Walker, 2014; Fryer, Ginns, Walker \& Nakao, 2012) and university students’ learning experiences situated online (Fryer \& Bovee, 2016; Fryer \& Bovee, 2014). These scales (four items each) measured deficits in ability beliefs (e.g., I didn't study because I don’t have what it takes to do well), effort (e.g., I didn't study because I am not energetic enough), task value (e.g., I didn't study because it was not important to me). Across the studies, responses to these three scales evinced strong reliability (Cronbach’s Alpha > .70), as well as clear convergent and divergent validity (consistently good fit for Confirmatory Factor Analyses).

The survey was proceeded with an explanation of the research project and an assurance that if students choose for their information to be included in the research project that it was no way related to their grade and their instructor would not have access to any identifiable information. The survey began with a stem (I don't study English 
because...) and each of the three scales contained four questions: Effort beliefs (e.g., I am not energetic; I am a bit lazy), Task valuation (e.g., I have no good reason; studying is not important); Ability beliefs (e.g., the tasks demanded of me surpass my abilities; I don’t have the knowledge to succeed in this course). Both the self-concept and in-class survey, assessing students' motivational deficits for studying, were measured on a summative rating scale of one to six, from "nothing like me" to "totally like me".

Attendance data was collected automatically with the use of "swipe-in and swipeout” IC chip devices, which all students touched their student ID cards to at the beginning and end of each class. All teachers participating in the study also gave weekly quizzes whose results were used to verify student attendance at the end of each semester.

\section{Analysis}

Analyses proceeded by assessing the reliability and convergent/divergent validity of all latent variables employed. Cronbach's alpha was assessed followed by a Confirmatory Factor Analysis (CFA) of all variables simultaneously. Finally, the hypothesised latent model was tested. All latent analyses were conducted with Mplus 7.0 (Muthén \& Muthén, 1998-2013). The Maximum Likelihood Robust (MLR) algorithm was used to obtain robust estimations of standard errors and to account for non-normality of observations. Prior to addressing missing data (12.1\%), Little’s MCAR (Missing Cases at Random) was used to test the hypothesis if the missing data was not random. The null hypothesis could not be rejected $\left(\chi^{2}=89.640\right.$, DF $\left.=100, p=.762\right)$, suggesting that Full Information Maximum Likelihood (FIML), rather than listwise deletion, was an appropriate means of addressing the missing data. FIML is generally held to be the most

effective means of dealing with reasonable amounts of missing data (Enders, 2010). 
For latent analyses, fit was assessed employing multiple fit indices. Root Mean Square Error of Approximation (RMSEA) (Browne \& Cudeck, 1992), with values <.08

and $<.05$ was used to indicate acceptable and good levels of fit respectively. Comparative Fit Index (CFI) values of $>.90$ and $>.95$ was used to indicate acceptable and good fit respectively (Marsh, Balla, \& McDonald, 1988. For the current study we relied on beta $(\beta)$ coefficient results to interpret structural equation modelling findings. Utilising Keith's (2015) suggested guidelines for interpretation of beta coefficients in research on influences on learning, betas below 0.05 are interpreted as "too small to be considered meaningful”; those above 0.05 are considered "small but meaningful”; those above 0.10 are considered “moderate”; and those above 0.25 are considered "large”.

\section{Results}

Average attendance for the three courses was relatively high (mean $=13.01$; $\mathrm{SD}=$ 2.15, out of 15 possible, averaged from three classes). All of the motivational deficits were above three except for task-value $($ mean $=2.78$; $\mathrm{SD}=.91)$. Students therefore perceived effort and ability beliefs to be reasons not to study. Students' average selfconcept was below the midpoint (mean $=2.60$; $\mathrm{SD}=.86$ ), suggesting that on average students did not feel confident in their English skills.

The reliability of all latent variables was acceptable (i.e. > .70 ; Devellis, 2012). Fit for the CFA of all variables together was good: $\mathrm{CFI}=.95, \mathrm{RMSEA}=.05(90 \%$ CI $.04-.06), \chi^{2}=249.57(150) p<.0001$, SRMR $=.047$. The correlations between the modelled variables from the inter-correlated model, the scale reliabilities, and scale score means and standard deviations are presented in Table 1. The correlational findings 
suggested that of the five prior variables modelled, only deficits in task-value $(r=.24 ; p$ $<.01)$ and prior competency $(r=.18 ; p<.01)$ were significantly related to students' class attendance.

-Table 1 ABOUT HERE-

To account for the strong relationship between the three motivational deficits modelled (task-value and ability beliefs $r=.69$; task value and effort beliefs $r=.71, p$ $<.01$; effort beliefs $r=.80, p<.01$ ) and their theoretical consistency, a higher order variable (amotivation) was included in the tested model. The hypothetical model fit the data acceptably: CFI $=.94$, SRMR $=.061$ RMSEA $=.06(90 \%$ CI $.04-.07), \chi^{2}=255.37$ (151) $p<.0001$ (Figure 3). A small drop in fit from the inter-correlated model to the hypothesised model is due to the removal of the inter-correlational paths between all constructs. This was necessary to enable a test of the hypothesised model consistent with longitudinal arrangement of students’ individual differences and course attendance. The finalised model with all tested paths is presented in Figure 3.

-Figure 3 ABOUT HERE

While actual proficiency was a moderate significant predictor of just one outcome variable (effort beliefs), self-concept predicted all future constructs modelled: ability beliefs $(\beta=-.54, p<.05)$, task value $(ß=-.26, p<.05)$, effort beliefs $(\beta=-.40, p<.05)$ and attendance $(ß=.25, p<.05)$. In addition to the direct regression of self-concept on attendance, its relationship with attendance was also partially mediated by the separate predictive effects of ability beliefs $(\beta=.52, p<.05)$ and effort beliefs $(\beta=-.42, p=.051)$. Task-value ( $\beta=.19$ ) was also a potential mediator, but failed to significantly predict class attendance $(p<.05)$. The model explained a moderate amount of variance for students' 
course attendance $\left(R^{2}=.17\right)$. See Table A for a complete presentation of effect sizes and $p$ values.

\section{Discussion}

The current study aimed to build on previous research regarding students’ class attendance at university, which suggested that individual differences (Credé et al., 2010), and motivation in particular (Clair, 1999), might be important predictors. The current study therefore modelled students' attendance in three courses of compulsory English as a foreign language (across two semesters of one academic year), students' deficits in task value, ability beliefs, effort beliefs for studying. In addition, students’ prior competency (actual and perceived competence measured at the end of the prior academic year) were tested simultaneously for their predictive validity for class attendance while controlling for gender. Structural equation modelling results indicated that in the current context, neither gender nor prior achievement were significant predictors of attendance. Modelling indicated that after accounting for prior competency (actual and perceived), ability belief related reasons for not studying were both predictors of failing to attend class. Ability belief deficits clearly predicted greater attendance: if perceived low competency is your reason for not studying, you are more likely to go to class. Effort belief deficits also presented a substantial $\beta$ for lower rates of attendance. While the significance of the $\beta$ was marginal, this additional finding indicated that if you feel that you just cannot be bothered to study, then you are also less likely to be bothered with going to class. Both mediated by and in addition to the role of motivational deficits, students' academic self-concept (but not actual prior listening/reading fluency) for the English language predicted greater class attendance. 


\section{General implications}

Credé et al. (2010) indicated that attendance plays a role in mediating the relationship between past and future achievement. The present study's results shift this theoretical alignment by pointing towards perceived competence rather than actual prior achievement. In the current study, after accounting for the large predictive contribution of self-concept, prior achievement failed to significantly predict future attendance. It is reasonable, however, to suggest that based on the tightly linked reciprocal nature of selfconcept and achievement (e.g., Marsh, Trautwein, Lüdtke, Köller, \& Baumert, 2005), that the role of prior achievement within future attendance might be partially mediated by self-concept. In addition to self-concept's direct relationship with attendance, it was also a substantial predictor of students' motivational deficits for studying. Self-concept predicted decreased deficits in ability/effort beliefs and task-value, in descending magnitude as listed.

An unexpected outcome of the model that may have implications for future theory development was the contrasting predictions of effort and ability beliefs for future attendance. Students who reported not studying for ability belief related reasons were more likely to go to class. The contextualised nature of the deficits measured ('I don't study because...') is likely what makes it a positive predictor of attendance. The unique nature of the construct is emphasised by the fact that self-concept negatively predicted ability belief deficits, but both constructs positively predicted class attendance. We suggest that ability deficits positively predict attendance after controlling for prior selfconcept, because students acknowledging their lack of ability for studying might be more likely to see class participation as a solution to this belief. In contrast to ability belief 
deficits, effort belief deficits had a negative relationship with attendance: if students cannot be "bothered" to study, they are also less likely to go to class. It appears that regardless of perceived ability, students' unwilling to expend the effort to study might not see class participation as a solution worth pursuing. After accounting for the role of these two deficits and prior actual/perceived competence, deficits in students' perceptions of the value of their studies had no direct significant role within class attendance. Task value's contribution to attendance might, however, be mediated by one or a combination of the other two deficits. Longitudinal modelling of students' motivations/beliefs for online studies has indicated that task-value deficits are partially mediated by ability beliefs (e.g., predicting course completion, Fryer \& Bovee, 2016). Across a year of university studies, longitudinal modelling of the regulation of students' studies and motivational deficits suggested that task-value deficits were an important predictor of future effort beliefs, while also playing an important role within the self-regulation of students’ studies (Fryer, Ginns \& Walker, 2016).

\section{Practical implications}

The question for university instructors is how these findings translate into supporting students in coming to class regularly. The current study does not add to the rules of thumb many past studies have commonly concluded with: e.g., not to emphasise the optional nature of attendance (e.g., Devadoss \& Foltz, 2009 ). Instead of heuristics, the current study provides empirical support for further theorising about the role of individual differences (Credé et al., 2010) and specifically motivation (Clair, 1999) within class attendance. The current findings suggest first that academic self-concept has a broad range of positive direct and potentially mediated relationships with attendance. A 
further finding points towards the varied role of different motivational deficits for studying. While instructors might see any source of motivational deficit as a problem, results from this study suggest that not all deficits in motivation are equal. If instructors are going to enhance class attendance then they need to target students who fail to study for effort-belief related reasons. There are many theoretical frameworks within which the question of effort-belief deficits might be addressed. Theories such as self-efficacy (Bandura, 1977, 1986, 1997), implicit theories of intelligence (Dweck \& Leggett, 1988) and more general approaches to perceived control questions (e.g., Skinner, 1995) all provide a strong body of empirical research from which instructors might draw upon for guidance. Each of these theories suggests a number of strategies for enhancing students' effort-beliefs with regard to learning. Theory (Bandura, 1977, 1986, 1997) and empirical research (e.g., Britner \& Pajares, 2006) have pointed to the essential role of mastery experiences for supporting self-efficacy development. Bandura (1977) theorised that students with "numerous and varied experiences of success” (Sherer \& Maddux, 1982, p.663) are likely to experience a stronger sense of self-efficacy.

Opportunities for experiences of success that can influence students' generalised expectancies in the same context can easily be integrated into learning contexts such as foreign language learning classes. Supporting students' self-efficacy takes a small shift in priorities for instructors: from "covering material” to ensuring every student "walks away from class with a sense of success”. Supporting increased opportunities for experiences of success can be as simple as ensuring that all classes have a few activities that every student can leave class having clearly succeeded at. For example, communication tasks which are structured, but still open to extensions for students who seek a challenge, can 
provide a means by which even a group of students of varied ability might all experience success sufficient to support self-efficacy development.

The benefits of stressing incremental over fixed implicit theories of intelligence is broadly recognised, and highlighted by a recent list of essential educational recommendations (APA, 2015). Interventions have established that students’ implicit theories can be enhanced through simple instructional interventions (Blackwell, 2007). In the present context of language learning, examples of instruction consistent with encouraging an incremental "mindset" would include framing course and class objectives in an incremental manner: e.g., "This course’s presentations will not be easy, it will take a great deal of independent and class study, but everyone can do well, if they put the necessary time in.”; or more generally, “Learning a language is like learning to ride a bicycle or learning to swim, it takes time and there will be many mistakes but everyone can do it.” Providing hope for delivering supports at a larger scale (beyond one class), recent research has suggested that these types of simple interventions might also be delivered online (Pauneska, 2015).

Students' perceptions of control (Skinner, 1995) is a theory we suggest might be utilised to understand and then support effort-beliefs and ability-beliefs in a given learning context. Students' perceptions of control include beliefs that the course goals are achievable and that effort is rewarded. Perceptions of control in a learning context support adaptive motivations for learning. Adaptive motivations for learning are then related to the kind of persistence necessary to support consistent attendance.

For instructors, the implementation of a clearly structured learning environment is perhaps the most effective means of enhancing perceived self-control: i.e., providing 
clear and reasonable pathways for students to succeed. For example, clear contingency is a major component of structure: ensuring students are provided with the information they need to achieve. Perceived control-supportive course structure ensures that students know what constitutes success at their given level and for each given task. It necessitates consistent feedback, not simply on instances of correct or incorrect, but also regarding students' development as language users. This kind of structure will give students the support they need to regulate their work effectively over the long-run (Skinner, 1991).

\section{Future Directions and Limitations}

There are a number of limitations to the present study that should be addressed in future research. First, as the current study was undertaken at one institution, careful replication of this study's findings are called for in both other universities in Japan and internationally. Second, only prior competence and attendance were based on observed variables, with the remaining four variables being self-reported. Third, there was a mandatory (2/3) attendance rule in place for the classes involved in the current study. This almost certainly played a role in the average high mean and moderate amount of variance explained by the model for attendance. Fourth, the present study did not include a measure of post competence, which is necessary if the study was to test the individual difference/attendance/achievement model hypothesised by Credé et al. (2010). Fifth, for the complexity of the latent model tested, the sample size was borderline. Finally, we

emphasis that further research is other domains (as well as other universities) is necessary before the external validity of the present findings can be resolved. For clear implications to be drawn regarding the complex moderating and mediating relationships between students' individual differences and their class attendance, a fully longitudinal design is 
necessary for both outcomes such as attendance and achievement as well as the individual differences (e.g., motivation) under examination.

\section{Conclusions}

Past theorising and empirical research have pointed toward individual differences in students' prior achievement and motivation as essential components of a model seeking to explain class attendance. Modelling in the current study has indicated that perceived competence, rather than actual prior achievement, supports students in attending class. Of the three types of deficits in students' motivation to study examined in the current study, ability (large positive) and effort (large negative) had strongly contrasting predictive relationships with class attendance. This study therefore highlights the potential benefits of enhancing students' self-concept for the domain under study, as well as supporting students' effort beliefs for studying the course materials. 


\section{References}

Abramson, L., Seligman, M., \& Teasdale, J. (1978). Learned helplessness in humans: critique and reformulation. Journal of Abnormal Psychology, 87, 49-74. doi: 10.1037/0021-843X.87.1.49

APA. (2015). Top 20 Principles from Psychology: For PreK-12 Teaching and Learning. Retrieved from http://www.apa.org/ed/schools/cpse/top-twenty-principles.pdf

Bandura, A. (1977). Self-efficacy - toward a unifying theory of behavioral change. Psychological Review, 84, 191-215. doi:10.1016/0146-6402(78)90002-4

Bandura, A. (1986). Social foundations of thought and action: A social cognitive theory. New York: Pearson.

Bandura, A. (1997). Self-Efficacy: The exercise of control. New York: Freeman.

Bati, A. H., Mandiracioglu, A., Orgun, F., \& Govsa, F. (2013). Why do students miss lectures? A study of lecture attendance amongst students of health science. YNEDT, 33, 596-601. doi:10.1016/j.nedt.2012.07.010

Blackwell, L., Trzesniewski, K., \& Dweck, C. S. (2007). Implicit theories of intelligence predict achievement across an adolescent transition: A longitudinal study and an intervention. Child Development, 78, 246-263. doi: 0.1111/j.14678624.2007.00995.x

Bovee, H. N., \& Fryer, L. K. (2011). オンライン CALL システムに関する開発経過 報告. 九州産業大学 COMMON, 31 
Britner, S. L., \& Pajares, F. (2006). Sources of science self-efficacy beliefs of middle school students. Journal of Research in Science Teaching, 43, 485-499. doi:10.1002/tea.20131

Browne, M., \& Cudeck, R. (1992). Alternative ways of assessing model fit. Sociological Methods \& Research, 21, 230-258. doi:10.1177/0049124192021002005

Chen, J., \& Lin, T. F. (2008 ). Class attendance and exam performance: A randomized experiment. The Journal of Economic Education, 39, 213-227. doi:10.3200/JECE.39.3.213-227

Clair, K. L. S. (1999). A case against compulsory class attendance policies in higher education. Innovative Higher Education, 23, 171-180.

Credé, M., Roch, S. G., \& Kieszczynka, U. M. (2010). Class attendance in college: A meta-analytic review of the relationship of class attendance with grades and student characteristics. Review of Educational Research, 80, 272-295. doi:10.3102/0034654310362998

Deci, E. L., \& Ryan, R. M. (1985). Intrinsic motivation and self-determination in human behavior. New York: Plenum.

Devadoss, S., \& Foltz, J. (2009 ). Evaluation of factors influencing student class attendance and performance. American Journal of Agricultural Economics, 78 499-507. Permanent link: http://www.jstor.org/stable/1243268

Devellis, R. F. (2012). Scale development: Theory and application (3rd ed.). Thousand Oaks, CA: Sage.

Doyon, P. (2001). A review of higher education reform in modern Japan. Higher Education, 41, 443-470. doi:10.1023/a:1017502308832 
Dweck, C. S., \& Leggett, E. L. (1988). A social cognitive approach to motivation and personaltiy. Psychological Review, 95, 256-273. doi:10.1037/0033-295X.95.2.256

Eccles, J., Adler, T. F., Futterman, R., Goff, S. B., Kaczala, C. M., Meece, J. L., \& Midgley, C. (1983). Expectancies, values, and academic behaviors. In J. T. Spence (Ed.), Achievement and achievement motives: Psychological and sociological approaches (pp. 75-146). San Francisco, CA: Freeman.

Enders, C. K. (2010 ). Applied missing data analysis. New York: Guilford Press.

Fay, R. E., Aguirre, R. V., \& Gash, P. W. (2013). Absenteeism and language learning: Does missing class matter? Journal of Language Teaching and Research, 4, 1-7.

Fryer, L. K., Ainley, M., \& Thompson, A. (2016). Modelling the links between students' interest in a domain, the tasks they experience and their interest in a course: Isn't interest what university is all about? Learning and Individual Differences, 50, 157-165. doi:10.1016/j.lindif.2016.08.011

Fryer, L. K., Ginns, P., \& Walker, R. W. (2016). Reciprocal modelling of Japanese university students' regulation strategies and motivational deficits for studying. Learning and Individual Differences, 51, 220-228. doi:10.1016/j.lindif.2016.08.032

Fryer, L. K., \& Bovee, H. N. (2016). Supporting students' motivation for e- learning: Teachers matter on and offline. Internet and Higher Education. doi:10.1016/j.iheduc.2016.03.003

Fryer, L. K. (2015). Predicting self-concept, interest and achievement for first-year students: The seeds of lifelong learning. Learning and Individual Differences, 38 1-9. doi:10.1016/j.lindif.2015.01.007 
Fryer, L. K., Bovee, H. N., \& Nakao, K. (2014). E-learning: Reasons students in language learning courses don't want to. Computers \& Education, 74, 26-36. doi:10.1016/j.compedu.2014.01.008

Fryer, L. K., Ginns, P., \& Walker, R. (2014). Between students’ instrumental goals and how they learn: Goal content is the gap to mind. British Journal of Educational Psychology, 84(4), 612-630. doi:10.1111/bjep.12052

Fryer, L. K., Ozono, S., Carter, P., Nakao, K., \& Anderson, C. J. (2013). Instrumental reasons for studying in compulsory English courses: I didn't come to university to study English so why should I? Innovation in Language Learning and Teaching, 00(00), 1-18. doi:10.1080/17501229.2013.835314

Fryer, L. K. (2013). Motivated study and learning strategies: Cross-sectional and longitudinal investigations. (Ph.D. Educational Psychology), Sydney University.

Fryer, L. K., Ginns, P., Walker, R. A., \& Nakao, K. (2012). The adaptation and validation of the CEQ and the R-SPQ-2F to the Japanese tertiary environment. British Journal of Educational Psychology, 82(4), 549-563. doi:10.1111/j.20448279.2011.02045.x

Fryer, L. K., Anderson, C. J., Stewart, J., Bovee, H. N., \& Gibson, A. (2010). Coordinating a vocabulary curriculum: Exploration, pilot, trial and future directions. Paper presented at the The Japan Association for Language Teaching National Conference, Nagoya, Japan.

Goodman, R. (2010). The rapid redrawing of boundaries in Japanese higher education. Japan Forum, 22, 65-87. doi:10.1080/09555803.2010.488944 
Green-Demers, I., Legault, L., Pelletier, D., \& Pelletier, L. (2008). Factorial invariance of the Academic Amotivation Inventory (AAI) across gender and grade in a sample of Canadian high school students. Educational and Psychological Measurement, 68, 862-880. doi:10.1177/0013164407313368

Hu, L. T., \& Bentler, P. M. (1999). Cutoff criteria for fit indexes in covariance structure analysis: Conventional criteria versus new alternatives. Structural equation modeling, 6, 1-55. doi:dx.doi.org/10.1080/10705519909540118

Hyde, R. M., \& Flournoy, D. (1986). A case against mandatory lecture attendance. Journal of Medical Education. 61, 175-176. Permanent link: http://journals.lww.com/academicmedicine/Fulltext/1986/03000/A_case_against_ mandatory_lecture_attendance_.5.aspx

Ichihara, M., \& Arai, K. (2004). The development of academic perceived competence and intrinsic interest: A cross-sectional study in Grade 4 through 9 students. Tsukuba Psychological Research, 27, 43-50.

Jung, J. Y. (2013). Amotivation and indecision in the decision-making processes associated with university entry. Research in Higher Education, 54, 115-136. http://dx.doi.org/ 10.1007/s11162-012-9267-2.

Keith, T. Z. (2015). Multiple regression and beyond: An introduction to multiple regression and structural equation modelling (2nd ed ). New York: Routledge.

Legault, L., Green-Demers, I., \& Pelletier, L. (2006). Why do high school students lack motivation in the classroom? Toward an understanding of academic amotivation and the role of social support. Journal of Educational Psychology, 98, 567-582. doi:10.1037/0022-0663.98.3.567 
Lotkowski, V. A., Robbins, S. B., \& Noeth, R. J. (2004). The role of academic and nonacademic factors in improving college retention: ACT policy report.

Marburger, D. R. (2006). Does mandatory attendance improve student performance? Journal of Economic Education, 37, 145-158. doi:10.3200/JECE.37.2.148-155

Marsh, H. W., Balla, J. R., \& McDonald, R. P. (1988). Goodness-of-it indexes in confirmatory factor-analysis: The effect of sample-size. Psychological Bulletin, 103, 391-410. doi:10.1037//0033-2909.103.3.391

Marsh, H. W., \& Shavelson, R. J. (1985). Self-concept: Its multifaceted hierarchical structure. Educational Psychologist, 20, 107-123. doi: 10.1207/s15326985ep2003_1

Marsh, H. W., Trautwein, U., Lüdtke, O., Köller, O., \& Baumert, J. (2005). Academic self - concept, interest, grades, and standardized test scores: Reciprocal effects models of causal ordering. Child Development, 76, 397-416. doi: 10.1111/j.14678624.2005.00853.x

Marsh, H. W., \& Yeung, A. S. ( 1997). Coursework selection: Relations to academic selfconcept and achievement. American Educational Research Journal, 34, 691-720. doi:10.3102/ 00028312034004691

Muthén, L. K., \& Muthén, B. O. (1998-2013). Mplus user's guide. (Sixth ed.). Los Angeles, CA: Muthén \& Muthén.

Newman-Ford, L. E., Fitzgibbon, K., Lloyd, S., \& Thomas, S. L. (2008). A large-scale investigation into the relationship between attendance and attainment: A study using an innovative, electronic attendance monitoring system. Studies in Higher Education, 33 699-717. doi:10.1080/03075070802457066 
No Author. (2015) TOEIC worldwide report. Retrieved from: https://www.ets.org/s/toeic/pdf/ww_data_report_unlweb.pdf

Murayama, K., \& Elliot, A. J. (2009). The joint influence of personal achievement goals and classroom goal structures on achievement-relevant outcomes. Journal of Educational Psychology, 101, 432-447. doi:10.1037/a0014221

Patrick, B. C., Skinner, E. A., \& Connell, J. P. (1993). What motivates children's behavior and emotion? Joint effects of perceived control and autonomy in the academic domain. Journal of Personality and Social Psychology, 65, 781-791.

Paunesku, D., Walton, G. M., Romero, C., Smith, E. N., Yeager, D. S., \& Dweck, C. S. (2015). Mind-set interventions are a scalable treatment for academic underachievement. Psychological Science, 26, 784-793.

doi:10.1177/0956797615571017

Pelletier, L., Dion, S., Tuson, K., \& Green-Demers, I. (1999). Why do people fail to adopt environemental behaviors- Toward a taxonomy of environmental amotivation. Journal of Applied Social Psychology, 29. 1-16. doi: 10.1111/j.1559-1816.1999.tb00122.x

Peterson, R. A., \& Brown, S. P. (2005). On the use of beta coefficients in meta-analysis. Journal of Applied Psychology, 90, 175-181. doi:10.1037/0021-9010.90.1.175

Ratelle, C. F., Guay, F., Vallerand, R. J., Larose, S., \& Senécal, C. (2007). Autonomous, controlled, and amotivated types of academic motivation: a person-oriented analysis. Journal of Educational Psychology, 99, 734-746. http://dx.doi.org/10.1037/0022-0663.99.4.734. 
Romer, D. (1993). Do students go to class? Should they? The Journal of Economic Perspectives, 7, 167-174. Permanent link: http://www.jstor.org/stable/2138449

Ryan, S. (2009). Ambivalence and commitment, liberation and challenge: investigating the attitudes of young Japanese people towards the learning of English. Journal of Multilingual and Multicultural Development, 30, 405-420.

doi:10.1080/01434630902928447

Sherer, M., Maddux, J. E., Mercandante, B., Prentice-Dunn, S., Jacobs, B., \& Rogers, R. W. (1982). The Self-Efficacy Scale: Construction and Validation. Psychological Reports, 51(2), 663-671. doi:10.2466/pr0.1982.51.2.663

Skinner, E. A. (1991). Development and perceived control - a dynamic-model of action in context. Minnesota Symposia on Child Psychology, 23, 167-216. Retrieved from $\leq$ Go to ISI $>$ ://A1991EU54600005

Skinner, E. A., Wellborn, J. G., \& Connell, J. P. (1990). What it takes to do well in school and whether I've got it: A process model of perceived control and children's engagement and achievement in school. Journal of Educational Psychology, 82, 22-32. doi:10.1037//0022-0663.82.1.22

Skinner, E. A. (1995). Perceived control, motivation, \& coping (Vol. 8). New York: Sage.

Stewart, J., Fryer, L. K., \& Gibson, A. (2013). Assessing the dimensionality of three hypothesized sub-skills of vocabulary proficiency. Japanese Journal of College English Teachers Journal. 56, 57-71. Permanent Online Location: http://ci.nii.ac.jp/vol_issue/nels/AA12208671/ISS0000489109_en.html 
Stewart, J., Gibson, A., \& Fryer, L. K. (2012 ). Examining the reliability of a TOEIC Bridge practice test under 1 and 3 parameter item response models. Shiken Research Bulletin, 16.

Vallerand, R. J., \& Bissonnette, R. (1992). Intrinsic, extrinsic, and amotivational styles as predictors of behavior: a predictor of behavior - a prospective study. Journal of Personality, 60, 599-620.

Vallerand, R. J., Fortier, M. S., \& Guay, F. (1997). Self-determination and persistence in a real-life setting: toward a motivational model of high school dropout. Journal of Personality and Social Psychology, 72, 1161-1176. http://dx.doi.org/10.1037//0022-3514.72.5.1161.

Vallerand, R. J., Pelletier, L. G., Blais, M. R., Briere, N. M., Senecal, C., \& Vallieres, E. F. (1992). The academic motivation scale: a measure of intrinsic, extrinsic and amotivation in education. Educational and Psychological Measurement, 52, 10031017. http://dx.doi.org/10.1177/0013164492052004025.

Vallerand, R. J., Pelletier, L. G., Blais, M. R., Briere, N. M., Senecal, C., \& Vallieres, E. F. (1993). On the assessment of intrinsic, extrinsic, and amotivation in education evidence on the concurrent and construct-validity of the academic motivation scale. Educational and Psychological Measurement, 53, 159-172. http://dx.doi.org/10.1177/ 0013164493053001018. 


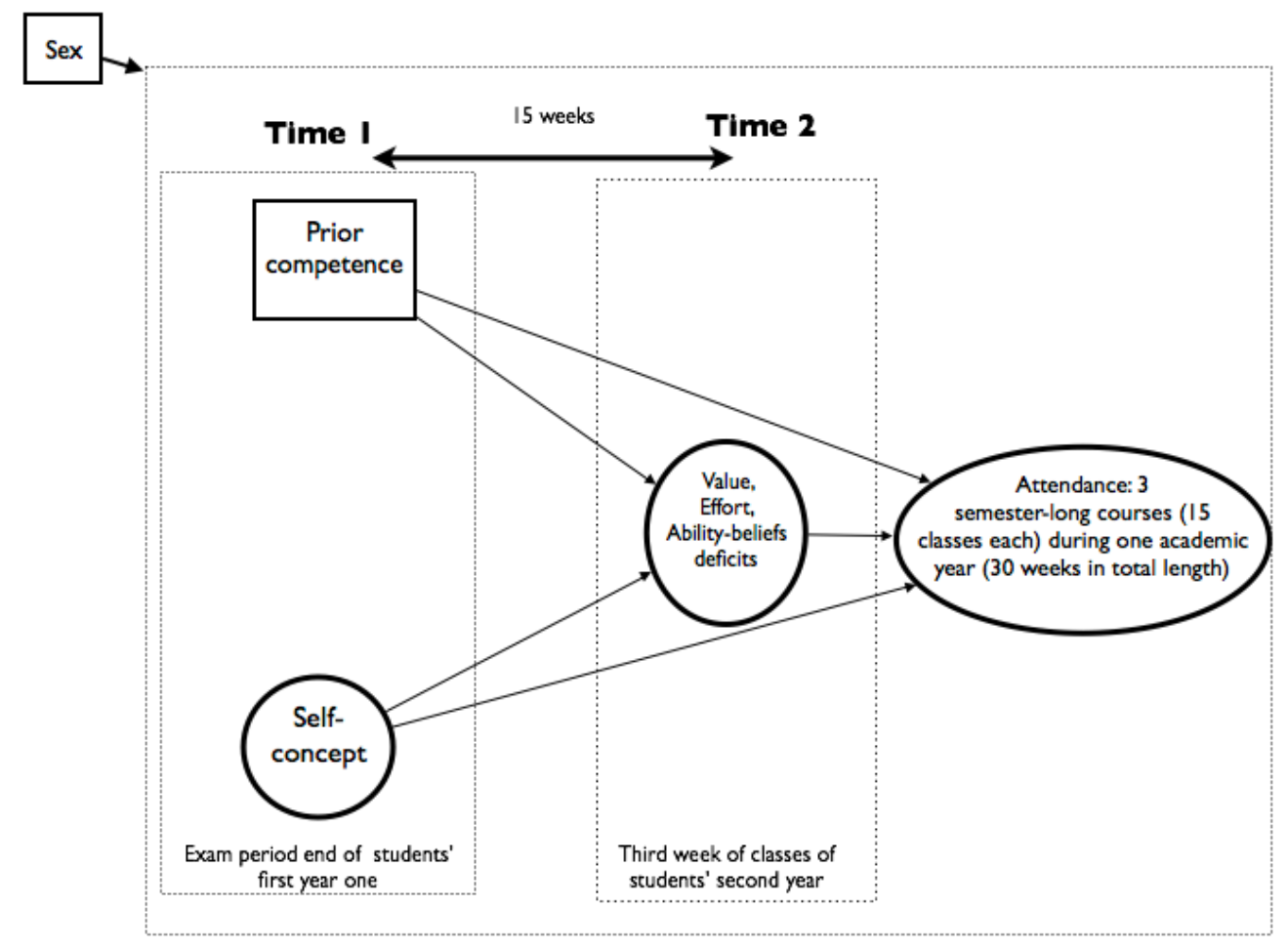

Figure 1. Hypothesised model

Note: $\mathrm{F} / \mathrm{M}$ refers to gender Female $=1$, Male $=2$. 


\begin{tabular}{llcl} 
Measurement & Time \\
\cline { 1 - 3 } Standardised English language test & Time 1 & Exam period of Year 1 \\
Motivation deficits & Time 2 & Third week of classes Year 2 \\
Attendance & & Three 15 week classes during Year 2
\end{tabular} 15 weeks weeks

Figure 2. Time order organisation of the current study 
Table 1.

Latent correlations, means, standard deviations and reliabilities

\begin{tabular}{|c|c|c|c|c|c|c|c|}
\hline & Gender & $\begin{array}{l}\text { Proficiency } \\
\text { pre-test }\end{array}$ & Self-concept & Task value & Effort beliefs & Ability beliefs & Attendance \\
\hline \multicolumn{8}{|l|}{ Gender } \\
\hline Proficiency pre-test & $-.15^{*}$ & & & & & & \\
\hline Self-concept & $-.35 *$ & $.26^{*}$ & & & & & \\
\hline Task value & .09 & $-.16^{*}$ & $-.28 *$ & & & & \\
\hline Effort beliefs & .03 & $-.28 * *$ & $-.43 * *$ & $.71^{* *}$ & & & \\
\hline Ability beliefs & -.03 & $-.25^{* *}$ & $-.54 * *$ & $.69^{* *}$ & $.80^{* *}$ & & \\
\hline Attendance & $.26 *$ & $.18^{*}$ & -.01 & $.24 * *$ & .09 & .13 & \\
\hline Mean & & 108.11 & 2.60 & 3.31 & 2.78 & 3.61 & $13.01(87.3 \%)$ \\
\hline Standard deviation & & 13.47 & .86 & .95 & .91 & .95 & 2.15 \\
\hline Cronbach's alpha for latent variables & & .91 & .86 & .82 & .85 & .82 & \\
\hline
\end{tabular}

Note: ${ }^{*} p<.05 ; * * p<.01$; Gender: F/M refers to gender Female $=1$, Male $=2$; Attendance (from 0 to 15) 


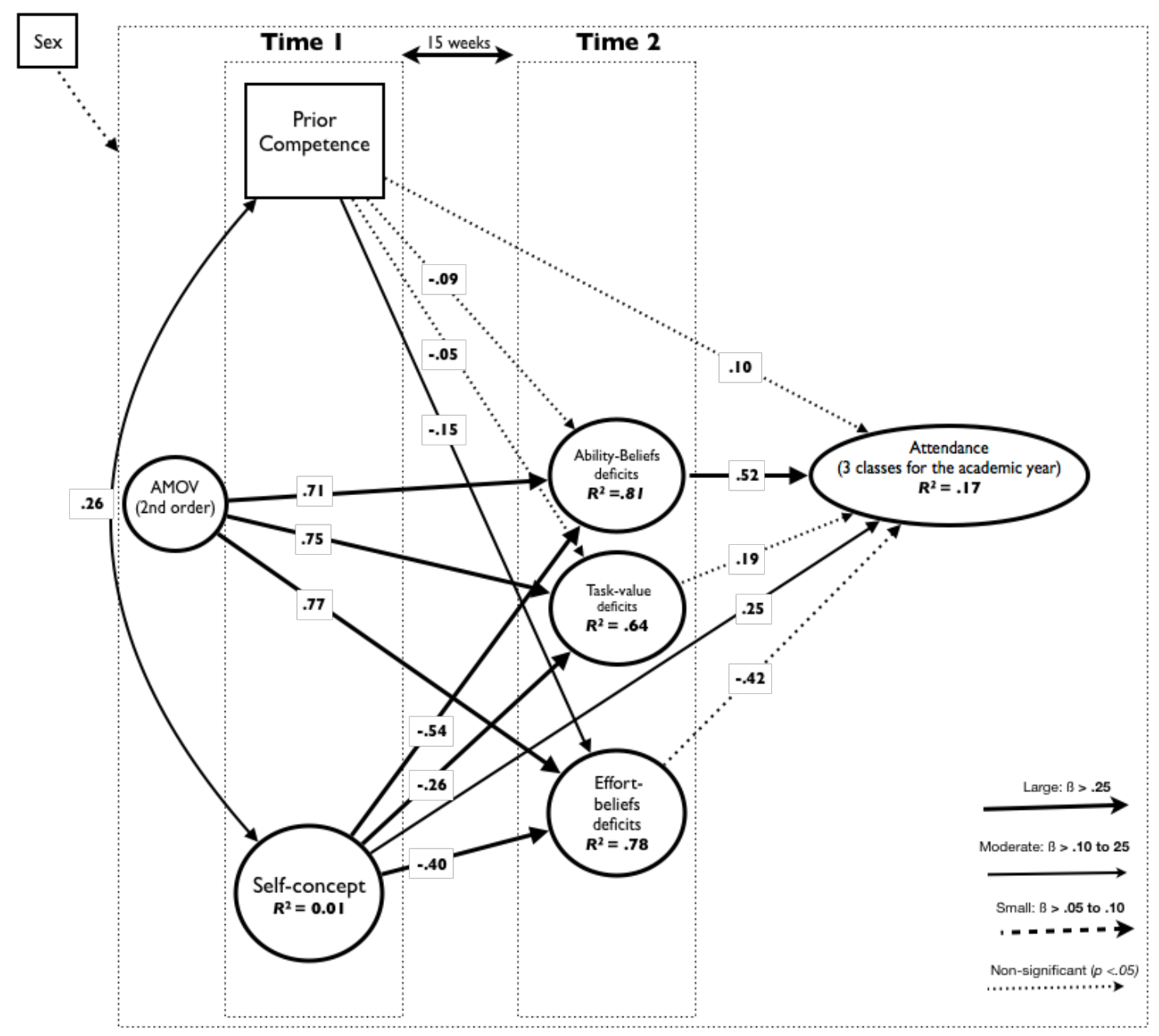

Figure 3. Hypothesised structural equation model tested Note: $\mathrm{F} / \mathrm{M}$ refers to gender Female $=1$, Male $=2$. Significance set a $p<.05$; no small ßs were observed. 


\section{Supplementary materials}

Table A. ßs for all forward tested paths with actual significance presented

\begin{tabular}{|c|c|c|c|c|c|c|c|c|c|c|c|c|}
\hline & & & & & & & & & Self-concept & Self-concept & Prior & Prior \\
\hline & Attendance (ß) & Attendance (p) & $\overline{\mathrm{AB}(ß)}$ & $\overline{\mathrm{AB}(\mathrm{p})}$ & $\overline{E F(ß)}$ & $\mathrm{EF}(\mathrm{p})$ & TV(ß) & $T V(p)$ & (ß) & (p) & competence (ß) & competence (p) \\
\hline$\overline{\mathrm{AB}}$ & .52 & .043 & & & & & & & & & & \\
\hline $\mathrm{EF}$ & .42 & .051 & & & & & & & & & & \\
\hline TV & .19 & .369 & & & & & & & & & & \\
\hline Self-concept & .25 & .040 & -.54 & .0001 & -.40 & .0001 & -.26 & .002 & & & & \\
\hline Prior competence & .10 & .279 & -.09 & .200 & -.15 & .038 & -.05 & .547 & & & & \\
\hline Sex & .11 & .310 & -.06 & .435 & -.02 & .773 & .05 & .538 & -.02 & .761 & -.11 & .097 \\
\hline
\end{tabular}

note: $\mathrm{AB}=$ ability beliefs, $\mathrm{TV}=$ task-value, $\mathrm{EF}=$ effort beliefs 